\title{
ОСОБЕННОСТИ ЗАИМСТВОВАНИЙ ФРАНЦУЗСКОГО ЯЗЫКА В ОБЛАСТИ КУЛЬТУРЫ, МОДЫ И КУЛИНАРИИ
}

\section{FEATURES OF BORROWING THE FRENCH LANGUAGE IN THE FIELD OF CULTURE, FASHION AND COOKING}

\section{E. Sharipova \\ N. Laletina \\ M. Zaichko}

Summary: There is not a single language whose vocabulary does not reveal borrowed words. Borrowed vocabulary can constitute up to $80 \%$ of the vocabulary in certain fields of activity. In different historical epochs, depending on the development of political, economic and socio-cultural relations, there was an intensive mutual penetration of lexical units. $A$ significant part of the borrowings in the Russian language are words and expressions that come from the French language or are formed according to the model of French words and expressions. The authors of the article analyzed the borrowed lexical units in the field of fashion, culture and culinary.

Keywords: french language, borrowings, lexical units, culture, fashion, cooking, word formation.
Шарипова Эльвира Маннуровна

К.с.н., дочент, Тюменский индустриальный университет elvira_sha2009@mail.ru

Лалетина Наталья Дмитриевна старший преподаватель, Тюменский индустриальный университет laletina2006@rambler.ru

Заччко Маргарита Васильевна старший преподаватель, Тюменский индустриальный университет rzaichko@mail.ru

Аннотация: Не существует ни одного языка, словарный запас которого не обнаружил бы заимствованных слов. Заимствованная лексика может составлять в определенных сферах до 80\% словаря. В различные исторические эпохи, в зависимости от развития политических, экономических и социокультурных отношений происходило интенсивное взаимное проникновение лексических единиц. Значительную часть заимствований в русском языке составляют слова и выражения, пришедшие из французского языка или образованные по модели французских слов и выражений. Авторы статьи провели анализ заимствованных лексических единиц в сфере моды, культуры и кулинарии.

Ключевые слова: французский язык, заимствования, лексические единицы, культура, мода, кулинария, словообразование.

тенденция избежать полисемию.

Если говорить об экстралингвистических факторах использования заимствований, то здесь, безусловно, нужно отметить политические, экономические и культурные связи между народами, социальную эволюцию внутри каждого социума, которые не могут не привести к лингвистическому обмену между носителями разных языков.

Лексикологи трактуют данное понятие как процесс передачи и перенимания лексических единиц из одного языка в другой [1]. Заимствованными называют все лексические единицы, пришедшие из другого языка вне зависимости от периода их адаптации и степени ассимиляции в другой язык [1].

Термин «заимствование» может использоваться в более широком смысле. Он подразумевает так называемые кальки и семантические заимствования. Кальки - это слова и выражения, композитом которых являются языковые единицы, сложенные по его моделям, но под влиянием иностранных слов и выражений. Так выражение «иметь место» в значении «происходить, состояться» является калькой от французского «avoir lieu» 
В процессе заимствования форма лексической единицы трансформируется в той или иной степени в процессе адаптации слова к фонетической системе принимающего языка, поскольку отсутствующие фонетические единицы заменяются на более или менее созвучные. Так, например, носовые звуки французского языка, которые являются характерными именно для этого языка и являются его «изюминкой», заменяются в русском языке на звуки [н] и [м], например слово «sentiments» с двумя носовыми [ă] звучит в русском языке как «сантименты». Проявлением фонетической адаптации может являться изменение места ударного слога. Во французском языке ударение всегда падает на завершающий слог, а в русском языке оно мобильное: «bijouterie»- «бижутерия» с ударением, падающим на третий, не последний слог[3].

Кроме фонетической звуковой трансформации, пришедшее из иностранного языка слово переживает также грамматическую адаптацию, которая может выражаться в изменение рода, исчезновении определенных служебных слов, предшествующих слову, как например артикль у существительных французского языка. Процесс адаптации может происходить без видимых осложнений, если грамматическая форма заимствованного слова соответствует морфологическим данным принимающего языка, как например, слова «le portraît» - «nортрет» - мужского рода в обоих языках или «la pièce» - «пьеса» - слова женского рода единственного числа. Но зачастую род и число заимствованных из другого языка существительных может не совпадать с первоисточником как, например, в словах: «la nature morte»дословно «мертвая природа»существительное и прилагательное женского рода, а в русском языке «натюрморт» - существительное мужского рода. При этом показателем рода и числа имени существительного во французском языке является артикль либо другое служебное слово, стоящее перед существительным, как например указательное или притяжательное прилагательное, а в русском языке - окончание [3].

Семантическая адаптация - изменение или искажение смысла заимствованного слова [1]. Например, заимствованное в XX веке из французского языка слово «jalousie» кардинально изменило свое значение, превратившись из абстрактного понятия «ревность, зависть» в «жалюзи», которые вешают, как альтернатива шторам на окна. Скорее всего, в этой адаптации есть некая логика, поскольку при помощи штор и жалюзи, люди прикрывают от чужих глаз свой жизненный уклад, свой достаток, благополучие, с целью избежать зависти недобрых людей. Еще один яркий пример, это название пирожного «эклер», пришедшего в русский язык от французского «е́clair», что в переводе означает «вспышка, молния» или не менее вкусное кондитерское изделие «безе», произошедшее от французского слова «baiser»- «nоцелуй», названного так, по всей видимости, из-за своей воздушности и легкости.
Следует подчеркнуть то, что в области моды, культуры, искусства и кулинарии русские словари заимствовали огромное количество слов. Это не вызывает большого удивления, поскольку именно в этих сферах между Францией и Россией были всегда и до сих пор остаются тесная взаимосвязь и сотрудничество. Так, в английский язык из французского языка пришло около 70\% вокабуляра в сфере военного искусства, что также можно объяснить большим количеством военных конфликтов между этими странами, соответственно и вынужденным взаимодействием языков, которое привело к заимствованиям именно в этой сфере.

Важно отметить то, что в кластере заимствованных слов, вошедших в русский язык из французского оригинала, особое место занимают галлицизмы. Галлицизмы (от лат. gallicus - галльский) - слова и выражения, заимствованные из французского языка или образованные по модели французских лексических единиц и выражений. Большая часть французских слов пришла в русский язык в эпоху деятельности Петра І, вклад которого в развитие российского образования, поднятия культурного уровня людей и технического прогресса невозможно переоценить, а также в постпетровскую эпоху, в частности в период правления не менее прогрессивной императрицы Екатерины II.

Пришедшая в русский язык французская лексика тематически может быть дифференцирована на множество групп. Авторы статьи не ставили целью ранжировать все группы заимствованных слов, а произвести обзор и ограничиться анализом заимствований в области моды, культуры и кулинарии.

В сфере моды Франция являлась и остается до сих пор эталоном для мировой, особенно европейской, в том числе и российской цивилизации. Само выражение «от кутюр», означающее высокую моду, произошло от французского «haute couture», что в дословном переводе означает «высокое швейное мастерство», отсюда и название главного действующего лица в этой сфере «сouturier»-«кутюрье». Слово «tricotage», произошло от французского глагола «tricoter», что означает «вязать (nри помощи спиц и нити)». Суффикс -age во французском языке используется для образования существительных, обозначающих какой-либо процесс или вид деятельности. Он активно используется так же для образования существительных в сфере кухни, кондитерии и кулинарии. «Corsage» - «Корсаж», слово заимствованное в первой половине XIX века, где «corsage» - суффиксальное производное от «соrps»- «тело»[5]. Французское словосочетание «bouquet de corsage», означает букет цветов, который надевали на верхнюю часть тела, как традиционный элемент туалета женщин на свадьбах и похоронах.

Слегка уже устаревающее в русском языке слово 
«кашне (uарф))» «cache-nez», произошло от французского глагола «сасher- nрятать» и «nеz- нос». Подобным способом, кстати, образовано и слово «кашпо», от того же глагола «сасher - nрятать» и слова «pot-горшок».

Большое количество заимствований пришло в русский язык в эпоху правления Петра I в XVIII веке, открывшего «окно» в Европу. Слово «панталоны» произошло от французского «pantalon», которое используется в современном французском языке значении «брюки», Заимствовано это слово в XVIII веке из французского языка, в который это слово пришло от собственного имени Pantaloni, героя итальянской комедии масок Панталоне, носившего широкие брюки [5].

«Гардеро́б» - заимствованное в XVIII веке сложное слово. Состоит из «garde»- «хранение» и «robe»-«одежда, платье».

«Шиньо́н» - «chignon» от латинского «catenio», котрое в свою очередь произошло от «сatena» - «цеnu». То есть буквальный перевод слова «щиньон»- изначально «цепочка», а впоследствие «коса» (по внешнему сходству). В современных словарях дается определение «шиньона» как «элемента женской прически» [5].

Следующие заимствования пришли в русский язык в XIX веке, когда социокультурные связи между Россией и Францией продолжались укрепляться.

«Декольте́» пришло в русский язык из французского языка в веке. «Décolleté» - причастие от глагола «décolleter»- «открывать шею». Корнем слова является слово «соl»- «шейка». Слово «соllier»- «колье» является однокоренным.

«Ма́рля» - слово заимствовано из французского языка, где «marli» от старофранцузского «marlé - meslé»«смешанный», от латинского «misculare»-«смешивать», того же корня, что «месить, смешивать». «Марля» буквально - «ткань из смешанной шерсти».

Слово «nальто́» пришло в русский язык в XIX веке. «Paletot» в испанском языке, который тоже относится, как и французский к романским - «paletoque» «плащ». В романские языки это слово пришло из латинского «parra», что означало «верхнее платье» [5]. .

К современным заимствованиям относится «Шифонье́р» - пришедшее в русские словари в Советскую эпоху. «Chiffonnière» - суффиксальное производное от «chiffon» - «тряпка, лоскут». «Шифоньер» буквально значит «шкаф для тряпок» [5].

Сфера кухни, кулинарии и кондитерии является, пожалуй, одной из самых изобилующих заимствованиями из французского языка. Следует заметить, что заимствования в этой области пополняют словарный запас достаточно интенсивно и в настоящее время. Современные кондитеры изобретают все новые и новые блюда, активно используя французские слова в качестве названий своих творений. Но процесс заимствований французских слов в этой области активно происходил примерно в ту же эпоху, что и в сфере моды - в XVIII-XIX веках. Многие из заимствованных существительных, являющихся кулинарной терминологией произошли от глаголов, обозначавших различные виды обработки и готовки продуктов. Так, например: слово «консе́рвы» - «conserve», является производным от «сonserver» «сохранять, консервировать». «Мусс» - «mousse», «мусс» или «пена» - от глагола «mousser» - «пениться». Примечательно, что однокоренным словом во французском языке является слово «мох». Название блюда «фрикасе́» - заимствованное в XVII веке слово «fricassée» - суффиксальное производное от глагола «fricasser», которое имеет значение «тушить, nоджаривать». Слово «суфле» - от французского глагола «souffler» - «дуть, задувать». Семантика слова подчеркивает легкость этого кондитерского изделия [4].

Вышеперечисленные лексические единицы являются примерами субстантивации глаголов, что чрезвычайно часто встречается в заимствованных словах в области кулинарии и кухни. Другими способами образования французских слов, пришедшими впоследствии в русский язык, являются: суффиксальный: один из самых интересных примеров слово «ресторан» - «restaurant», причастие настоящего времени от «restaurer» - «подкреплять, восстанавливать силы».

Также часто использовался способ сложения двух слов, то есть образование сложных слов: «антрекот»«entrecôte»: от пространственного предлога «entre» «между» и существительное «сôte» - «кость,ребро».

Интересен феномен метонимического переноса французских собственных имён, которые позже были в исходном виде заимствованы в русский язык. Многие названия алкогольных напитков произошли от собственных имен - названий городов, провинций и поселений, где они были произведены. «Коньяк»- название французского города, в котором начали производство этого напитка, получившего мировое признание. «Фужер» - по названию города, в котором производили стекло, для производства особой формы стаканов для употребления алкогольных игристых напитков. Зачастую имена создателей блюд становились названиями блюд, как это случилось со словами «бешамель»- «béchamel» от фамилии Louis de Béchamel. Или «пралине» «praliné» - по фамилии маршала Плесси-Пралена, который был очень значим для короля Людовика XIV. Когда однажды маршал серьезно заболел, король лично захотел посетить заболевшего маршала, в знак большого уважения. 
Кондитер, служивший у маршала, приготовил в качестве угощения обжаренный и обсыпанный сахаром миндаль. Десерт очень понравился королю, и получил свое распространение под именем маршала Пралена.

Таким образом, можно утверждать, что французский язык значительно обогатил русский язык в сфере моды, культуры и кулинарии. Знание этимологии заимствований, тенденций их словообразования, является мотивационной составляющей для изучающих французский язык, к повышению лингвострановедческих знаний и облегчает освоение лексико-грамматических навыков.

\section{ЛИТЕРАТУРА}

1. Ильина 0.В. Семантическое освоение русским языком иноязычных лексических инноваций (на материале газетных текстов 1990-1995 гг.) // Языковые единицы в семантическом и лексикографическом аспектах. - Новосибирск, 1998. - С. 41-48

2. Литературный энциклопедический словарь [Электронный ресурс] - URL: https://literary_encyclopedia.academic.ru/6959 (дата 0бращения: 09.08.2021).

3. Мурия, М.Р. Французские заимствования в русском языке / М.Р. Мурия, Е.В. Мартемьянова, Е.В. Конюхова. — Текст: непосредственный // Юный ученый. — 2017. — № 3 (12). — C. 112-114. — URL: https://moluch.ru/young/archive/12/958/ (дата обращения: 03.09.2021).

4. Ожегов С.А., Шведова Н.Ю. Толковый словарь русского языка 80000 слов и фразеологических выражений/ Российская академия наук. Институт русского языка им. В.В. Виноградова. - 4-е издание дополненное. Москва: Азбуковник, 1997. 944 с.

5. Этимологический онлайн-словарь русского языка Шанского H.M [Электронный ресурс] - URL: https://lexicography.online/etymology/shansky (дата обращения: 09.08.2021).

() Шарипова Эльвира Маннуровна (elvira_sha2009@mail.ru), Лалетина Наталья Дмитриевна (laletina2006@rambler.ru), Заичко Маргарита Васильевна (rzaichko@mail.ru).

Журнал «Современная наука: актуальные проблемы теории и практики»

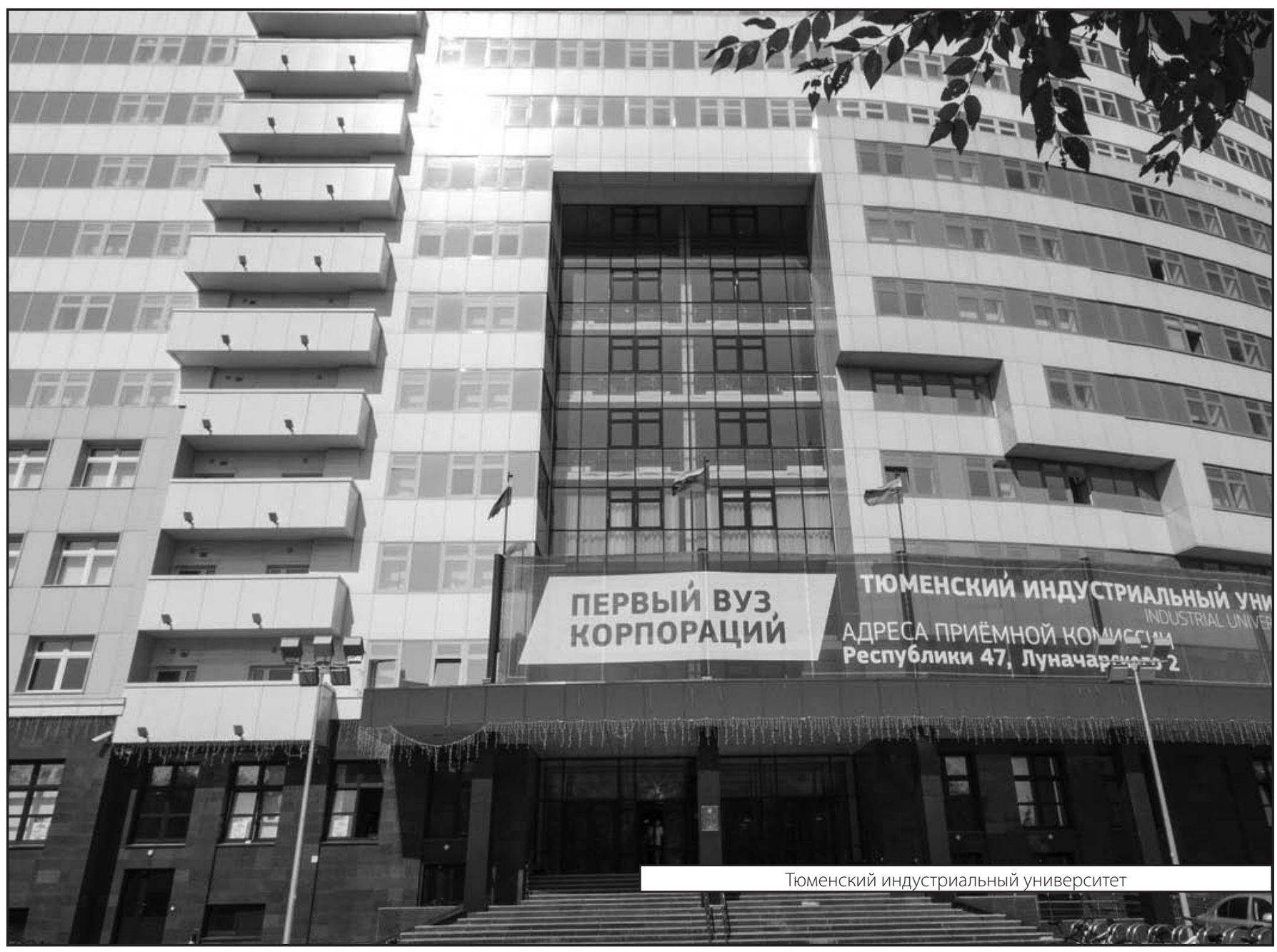

